\title{
Implementing M-Learning System for Learning Mathematics Through Computer Games and Applying Neural Networks for Content Similarity Analysis of an Integrated Social Network
}

\author{
https://doi.org/10.3991/ijim.v15i13.22185 \\ Petar Juric $\left.{ }^{(}\right)$, Marija Brkic Bakaric, Maja Matetic \\ University of Rijeka, Rijeka, Croatia \\ petar_jur@yahoo.com
}

\begin{abstract}
In order to make e-learning systems widely available, the majority of new systems are being developed in a form suitable for m-learning. The system implemented in this research uses educational computer games for learning Mathematics in primary schools and has an integrated social network, which is used for communication and publishing game-related content. The system is not restricted to desktop platforms, but provides equivalent user experience and functionality on smartphones and tablets. The research highlights the challenges involved in developing the system and illustrates the process of adapting the elearning system to m-learning. Besides analyzing platforms used for accessing the system (desktop/mobile), the paper also explores how to interpret messages when they contain concepts which are in a student jargon or generally unknown to teachers, and shows that these messages can be interpreted by applying neural networks.
\end{abstract}

Keywords - m-learning, e-learning, game-based learning, Mathematics, neural networks, social network analysis

\section{$1 \quad$ Introduction}

Previous researches have been mostly based on native applications for which direct data acquisition is hindered by an increase in the number of users. Therefore, more frequent use of web-based mobile learning (m-learning) is to be expected. The users of web applications access applications through their Internet browsers using URLs, while native applications have to be downloaded and installed on user devices. Web applications, therefore, ensure that applications are always up-to-date, unlike native applications, which are distributed and updated through dominant operating system providers, i.e. Google (Android) and Apple (iOS). The resulting fragmentation of the development environment can slow down the development of native applications.

Web-based mobile learning applications appeared in 2014, after the new web standard HTML5 was issued. Unlike its predecessor HTML4, HTML5 supports new APIs used for accessing mobile device sensors in the web environment, and includes a 
number of new elements necessary for e-learning, such as audio, video, canvas (for graphics and games), etc. [1]. Another important component that contributed to the acceptance of web-based mobile learning is responsive design using CSS (Cascading Style Sheet). The same content can be displayed irrespective of the screen size and platform [2].

E-learning is usually stationary with respect to the location, and it takes place in front of computers within school or home environments. M-learning enables students to choose their learning location, which can be even outdoors or while on the go. It can be assumed that learning systems that ensure equivalent e-learning and m-learning experience can be built by utilizing responsive web technologies. Such systems would be more accessible and adapted to different learning styles. Considering the fact that majority of research studies deal with e-learning separately from m-learning, one of the first goals of the research study presented in this paper is to demonstrate the process of adapting a system to ensure the equivalence of e-learning and m-learning user experience, and pinpoint potential difficulties on the system for learning primary school Mathematics through computer games. The second goal is to analyze the data collected within the research study in order to detect which of the two learning forms is preferred among students when they are allowed to use whatever suits them better at any particular point of time.

A social network is integrated into the system. Social networks are used to make the learning innovative and stimulating, particularly in the case of m-learning [3]. The utilization of social networks opens up possibilities for the analysis of data generated by these social networks. For teachers, communication over social networks might sometimes be hard to decipher because students tend to use abbreviations or jargon. Therefore, the third goal of this research is to explore the possibilities of deciphering such messages by applying neural networks, in order to help teachers, gain insight into such messages.

Due to personal data protection regulations, using social networks in primary schools is underexplored and there are not that many research studies dealing with it. For the purpose of this research, the m-learning system that uses educational computer games is integrated with a private social network which has access to anonymized studentrelated features.

The remainder of the paper is structured as follows. Related work is presented in section 2. Section 3 introduces questions explored by the research presented in the paper. Methodology is presented in section 4 and subdivided into subsections relating to the technology utilized in the implementation of the system, support for posting microblog messages, methods used for social network text analysis, and description of the dataset. Results in terms of introduced adaptations to the system, analysis of platforms used for accessing the system, and analysis of the microblog service content are presented in section 5. Limitations and future work are discussed in section 6. Conclusion is presented in the last section of the paper. 


\section{Related Work}

This section presents a review of the related work in the field of e-learning and m-learning with respect to adoption and availability. It also presents research on the analysis of social network data in education, with a reflection on its use in the education process.

\subsection{Relationship between e-learning and m-learning}

E-learning systems first occurred at the end of 80 s of the last century with the development of technology and wider availability of personal computers. The letter ' $\mathrm{e}$ ' in the term e-learning refers to the way of learning, i.e. it means that the content is digitalized and stored electronically, while the process of learning can be adapted to each individual [4]. E-learning systems used to contain textual materials supplemented with figures and other forms of multimedia, and content used to be stored on optical media [5]. Internet enabled delivering multimedia content via web-based learning [6].

There are many different definitions relating to e-learning systems. By taking into account interactions within e-learning systems, engagement of instructors, and time needed for finishing a course, e-learning systems can be divided into synchronous, asynchronous, and cohort [7]. Synchronous implies instructors and students being present at the same time, like in the classic education, but not necessarily at the same place. In synchronous systems, instructors can connect with students over platforms that support virtual classrooms, so students can listen to the lectures and share screens with their instructors, while communication takes place through chat (short messages written in real time). Asynchronous is the opposite of synchronous in terms of the teaching form and the presence of instructor, and it is intended for self-learning. An example of asynchronous teaching in the classic education is homework. In e-learning, asynchronous relates to the possibility to access content any time. In cohort e-learning, instructors are present and the time needed for content acquisition and mastering any given course is suggested. Students can participate in discussions and analyze materials in their daily or weekly schedule, but the materials uploaded by instructors can be accessed at time convenient to students, and not necessarily in real-time. Public online courses (MOOC - Massive Open On-line Course) intended for a large number of users are the most common representative of this kind of learning.

In e-learning systems, interactivity and the possibility of user cooperation can have a stimulating effect on the engagement of users and their interest for using the system [8].

Unlike e-learning, which is accessible from desktop platforms (mostly desktop computers and laptops with Windows, Mac OS X and Linux operating systems), mlearning is available using mobile platforms, i.e. smart mobile devices (mostly with Android and iOS mobile operating systems). Smart mobile devices are phones or tablets with mobile operating systems that have standardized user interfaces, platforms for the development of applications, and Internet browsers. They also support multimedia reproduction and location services. Besides built-in microphones and cameras, there are also built-in sensors (acceleration, gyroscope, orientation) which detect physical 
activity [9]. This opens up new possibilities for creating educational materials. Additionally, m-learning complements e-learning with the possibility to use the system anywhere and anytime [10], and the possibility to learn while on the go.

In order to enable school learning over computers, followed by learning over smart mobile devices in buses on the way home, and then home learning over computers, technologies such as HTML5 eco-system in the responsive design have to be used on the client side. For the development of applications, and thereby digital educational materials, such technologies alleviate problems caused by the fragmentation of the operating platforms and devices (different versions of operating systems, different dimensions and screen resolutions).

The utilization of m-learning in primary and secondary schools is, alongside many advantages, faced with numerous challenges which, among others, stem from the unavailability of broadband Internet in schools of distant rural areas, as well as the need to prevent children from accessing inappropriate content (Table 1) [11].

Table 1. Advantages and disadvantages of m-learning systems in primary and secondary schools

\begin{tabular}{|l|l|}
\hline \multicolumn{1}{|c|}{ Advantages } & \multicolumn{1}{|c|}{ Disadvantages } \\
\hline Learning on the go & Supervised use \\
\hline $\begin{array}{l}\text { Availability to a larger number of students - weak } \\
\text { models of mobile devices (telephones, tablets) are } \\
\text { cheaper than computers }\end{array}$ & $\begin{array}{l}\text { Availability of devices and Internet access - tablets } \\
\text { are more affordable than computers, but still more } \\
\text { expensive than schoolbooks }\end{array}$ \\
\hline $\begin{array}{l}\text { Development of higher levels of cognitive abilities - } \\
\text { critical thinking, problem solving, creativity, } \\
\text { innovations, etc. }\end{array}$ & $\begin{array}{l}\text { Use of technology can distract attention during } \\
\text { classes }\end{array}$ \\
\hline $\begin{array}{l}\text { Support for alternative forms of teaching in and out } \\
\text { of the classroom }\end{array}$ & $\begin{array}{l}\text { Virtual keyboard is more difficult to use than the } \\
\text { classic, physical keyboard }\end{array}$ \\
\hline $\begin{array}{l}\text { Personalization possibilities - easier to keep track of } \\
\text { each individual progress }\end{array}$ & $\begin{array}{l}\text { Positive effects cancel out if the same mobile device } \\
\text { is shared by multiple students }\end{array}$ \\
\hline $\begin{array}{l}\text { Positive effect on motivation - high level of } \\
\text { autonomy due to using new technologies }\end{array}$ & $\begin{array}{l}\text { Mere replacement of the medium for information } \\
\text { transmission on mobile devices does not result in the } \\
\text { desired positive effects }\end{array}$ \\
\hline
\end{tabular}

A shift in the research related to higher education occurred in 2010, when smartphones and technology acceptance became more widespread [12]. M-learning is utilized at universities as one of the new forms of teaching. Advantages of good practice are analyzed in [13].

The number of students using smartphones for learning is constantly increasing. For example, in the research conducted by [14], there were $10.4 \%$ of students using smartphones for learning in the academic year 2015/2016, while the percentage increased to $61.5 \%$ in $2019 / 2020$.

Collaborative mobile learning (CML) can have a positive effect on student satisfaction with the education process. While ensuring the development of students' communication skills, CML also facilitates learning through the exchange of ideas and knowledge [15].

The authors in [16] show that pre-service teachers' attitudes toward the usefulness of m-learning and the perceived ease of use most strongly impact their m-learning 
acceptance. High-level skills and experience in mobile technology prove to be crucial for the adoption of mobile devices as instructional tools by future pre-service teachers due to the impact they have on the perception of usefulness and ease of use.

Smart mobile devices can be used in the learning by doing approach. With the goal to develop computational thinking and learn robotics, children can be given robots and robotic kits at early childhood and during initial grades of the primary school. For remote controlling and programming of robots and robotic kits, applications on smart mobile devices can be used [17].

Using mobile devices for navigating through real-life paths in which mathematical problems are solved facilitates learning of primary school Mathematics [18].

Teachers need to be trained to successfully incorporate m-learning into their pedagogical practice. The actual impact of m-learning programs is not simply intensification of educational effects. Technology and curriculum need to be more closely integrated, and higher-level skills need to be further assessed. M-learning providers must improve the user friendliness and ease of use of their m-learning systems in order to attract more users, because teachers' adoption of technology may be hindered by more than simply accessibility issues [19].

\subsection{Social networks in education}

E-learning and m-learning systems can employ social networks either as independent teaching methods or as supplements to learning systems. Social networks can be used for collaboration between participants of the education process.

The most significant advantage of using Twitter in education is the form of posts. Alongside enabling teachers to send important information related to their courses, homework, and deadlines, it enables students to cooperate [20].

Beside textual data, social networks are sources of additional information on the content and users. Each tweet record reveals information on over 150 features [21].

By using social networks in the process of learning, students not only learn or receive information, but also communicate with their teachers and other students, and become active participants in creating intellectual products [22].

Since Twitter helps university students more readily participate in discussions, in comparison with in-class discussions, it facilitates the development of critical thinking and confrontation of opinions [23].

The analysis of short answer type of exam questions can be conducted by applying text mining methods [24]. The utilization of these methods enables obtaining grade prediction models and meaningful feedback [25]. Sentiment analysis related to university-level classes and teaching staff can be conducted by applying neural networks [26]. Besides, social network data analysis on a university level enables the detection of strong connections between assimilative and productive activities, as well as activities of finding information. Data provides educators with explicit feedbacks on their learning designs, which allows them to reflect on current practices and predict potential problems, e.g. in order to increase students' engagement, educators may introduce more communication-related activities [27]. 
Sentiment analysis of short messages is challenging due to a limit on the number of characters, which results in using abbreviations, slang or hashtags whenever possible. Acosta et al. in [28] use word embeddings obtained by the word2vec algorithm in order to classify sentiment.

Related work shows that successful and efficient implementations of e-learning and m-learning require interesting and widely available learning materials without any sacrifice in functionality. However, it remains unclear which technologies and components should be utilized in order to achieve it. Furthermore, there are no reflections on student collaboration over social networks in cases in which their attitudes might be blurred or ambiguous due to a lack of familiarity with the abbreviations and jargon used. The research hypotheses presented in the following sections are based on these observations.

\section{Research Questions}

The research presented in this paper analyses platforms (desktop/mobile) used for accessing the e-learning system, which is based on educational computer games for learning Mathematics in primary schools. The system retains its full functionality in its m-learning form, which facilitates its wider availability. In line with the first research goal, the process of adaptation is presented in section 5.1.

In line with the second research goal, the question analyzed is, if given a choice, which of the platforms will be more often used by students. The following hypothesis is formulated: for young generations, m-learning Mathematics through educational computer games is more acceptable than e-learning. The hypothesis will be accepted if there is a significant difference in accessing the system for learning primary school Mathematics through educational computer games from mobile platforms as opposed to desktop platforms.

In order to explore the possibilities of utilizing technologically assisted collaboration and group work in class, an adapted social network based on the microblog service is integrated into the system. Due to the observed difficulty in detecting sentiment and meanings of messages in student communication over social networks as a result of using abbreviations, making up new concepts, and using sign language, the third research goal is set and the question whether these messages can be interpreted by applying neural networks is explored.

\section{Methodology}

The dataset used within this research is collected from the interaction of students with a computer game. The features taken into account include game elements used for solving problems, number of games played, number of levels passed, etc. Beside these game-related features, timestamp of each record and platform (desktop or mobile) used for accessing the system are also taken into account.

Alongside playing the game, students have the chance to post messages on the social network integrated into the system. For personal data protection reasons, contents of 
messages are purely textual, without the possibility to include images, audio, or video clips. Similarly, to game records, each record is supplemented with timestamp and platform. Message content analysis is conducted based on word2vec neural network models.

\subsection{Technologies used}

Most of the research in the field of m-learning through computer games is based on native applications for smart mobile devices. These applications are not ready for use on desktop computers and laptops without developing platform-specific versions.

In order to make the system available to a wider circle of students and teachers, an important requirement set out during the development is that it can be used on all the dominant desktop and mobile platforms. With the above-said in mind, several opensource technologies are used and integrated into the system. The backbone of the system is Phaser [29], which is one of the most popular environments for the development of web games for mobile devices and desktop computers. It has already been used in the development of games such as Otismo [30] intended for children with autism, in order to attract their attention through games, or for IoT education [31].

\subsection{Posting microblog messages}

The model implemented within this research is based on the microblog platform. Although it resembles to Twitter, it does not collect personal data for data protection reasons. The model enables posting short messages (maximum 160 characters) without additional logins because messages are posted from the game within the m-learning system. The process of sending messages is shown in Fig. 1.

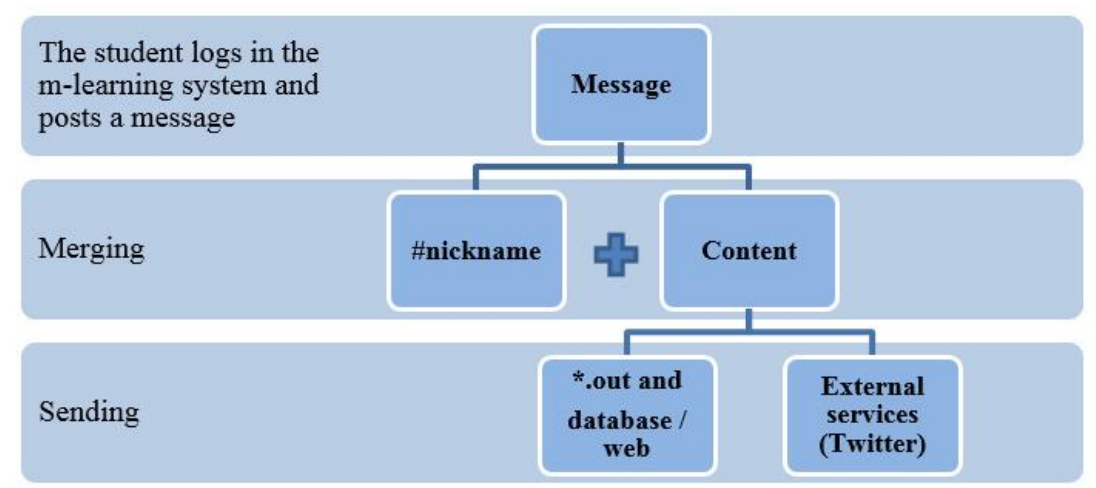

Fig. 1. The process of sending a message in the implemented microblog service

Message content is first connected to the nickname from the m-learning system in order to keep track of the authors of messages and make threads of messages posted by the same author, and then sent to the database or external services. 


\subsection{Neural networks for social network text analysis}

Neural networks algorithms that analyze text based on similarity (comparing words) are used for the microblog service data analysis, i.e. social network data analysis. More precisely, word2vec model in the tool KNIME [32] is used.

In comparison to the majority of natural language processing techniques, which analyze words irrespective of their position, this model takes into account the position of the word within the sentence and its relationships to other surrounding words.

Word2vec uses two approaches in solving the problem: CBOW (Continuous-BagOf-Words) and skip-gram [33]. CBOW predicts the vector of a target word based on the window of surrounding words, while skip-gram predicts words that surround the target word and it is inverse to CBOW. Word2vec deals with classification problems. Therefore, its aim is to maximize the classifier accuracy. Fig. 2 shows CBOW and skipgram models on an example of a message posted on the social network. Variable $w$ stands for the weight of the word in step $t$.

The word2vec model calculates distances between a word and other words and tries to predict those that are closest. Negative samples are used for updating the model based on the errors observed. This type of machine learning falls into the category of semisupervised learning. A positive pair based on the example given in Fig. 2 in relation to the word 'game' (igra) and by taking into account the surrounding words would be $(($ igra,$j e), 1)$, where je means 'is', while a negative sample pair would be ((igra, bravo), 0 ), where bravo means 'well-done'.
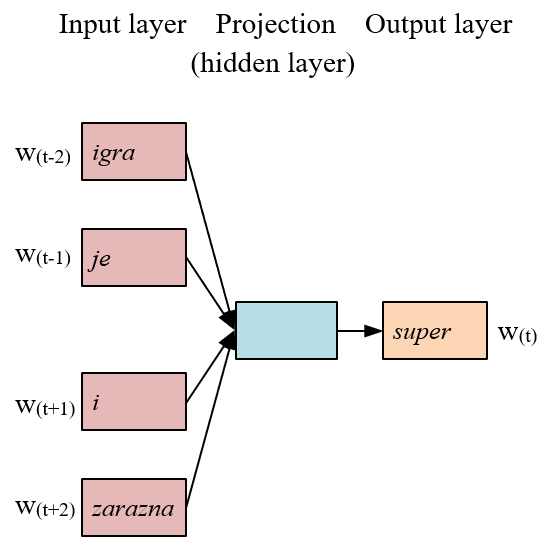

CBOW
Input layer Projection Output layer (hidden layer)

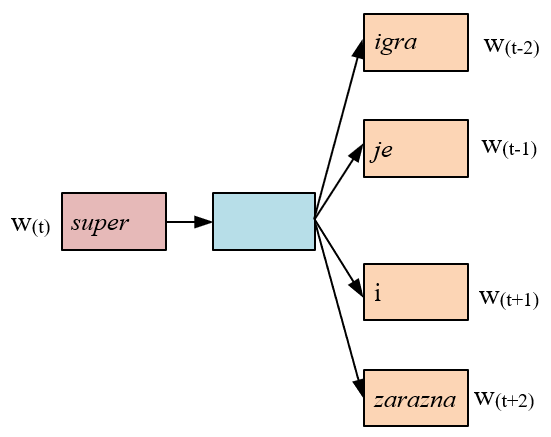

skip-gram

Fig. 2. The architecture of CBOW and skip-gram in the implemented model

Word2vec uses input, output, and hidden layer neural networks. The model belongs to the category of shallow neural networks as it uses only three layers [34].

CBOW (1) and skip-gram (2) models can be formalized in the following way:

$$
\mathrm{J}_{\varnothing}=\frac{1}{\mathrm{~T}} \sum_{\mathrm{t}=1}^{\mathrm{T}} \log _{\mathrm{p}}\left(\mathrm{w}_{\mathrm{t}} \mid \mathrm{w}_{\mathrm{t}-\mathrm{n}}, \ldots, \mathrm{w}_{\mathrm{t}-1}, \ldots, \mathrm{w}_{\mathrm{t}+1}, \ldots \mathrm{w}_{\mathrm{t}+\mathrm{n}}\right)
$$




$$
\mathrm{J}_{\varnothing}=\frac{1}{\mathrm{~T}} \sum_{\mathrm{t}=1}^{\mathrm{T}} \sum_{-\mathrm{n} \leq \mathrm{j} \leq \mathrm{n}} \log _{\mathrm{p}}\left(\mathrm{w}_{\mathrm{t}+\mathrm{j}} \mid \mathrm{w}_{\mathrm{t}}\right)
$$

where $p$ stands for probability, $t$ for step, and $n$ for the window composed of the words which surround the target word [35].

\subsection{Dataset}

Logging in is anonymized using nicknames based on the model given in [36].

The total number of students included in this research is 104. The students take classes in Mathematics and they are in higher grades (5-8) of a primary school in the Republic of Croatia. They are all between 11 and 14 years old. The period covered by the research includes one week prior to winter holidays, three weeks of holidays, and two weeks after holidays of the academic year 2017/2018.

\section{$5 \quad$ Results}

\subsection{Adapting the system to ensure equivalence of e-learning and m-learning}

For the purpose of this research, the computer game Zagonetke mudrog lisca (Riddles of the wise fox) has been developed and integrated into the m-learning system. The game is intended for primary school students and covers problem tasks in Mathematics that are based on Roman numerals.

In order to make the game available on both desktop and mobile platforms in full screen (the interface visually complies with a native application), and taking into account the space used up by the URL in the browser, scaling is enabled even in resolutions different from the full HD standard $(1920 \times 1080)$. This enables playing the game on older smart mobile devices (production year < 2016), which have lower screen resolutions, without any loss of information on the interface. Additionally, several corrections have been made to the initial version of the game in order to achieve $100 \%$ rendering availability. Rendering is, therefore, predefined to be of the Canvas type, considering the fact that WebGL (which can significantly speed up working with graphics and animations) on older devices leads to screen flickering which makes playing the game impossible.

Automatic scaling over the whole screen is implemented in a way to make it independent of mobile device orientations (landscape, portrait). This ensures that the whole display area of graphical objects on the Canvas element in the range from minimum to maximum values is always visible. A drawback of this approach might be evident with non-standard mobile device screen resolutions which do not have default ratios or when the game is not played in full screen on desktop computers. The space surplus is automatically displayed in black which does not lead to a loss in the quantity of displayed content, but only to its scaling towards lower values, which is why the 
content becomes smaller and harder to perceive. Consequently, the implemented physical models of objects necessary for the interaction and solving problem tasks in the game have smaller dimensions regarding the number of used pixels, which can result in lower interaction accuracy.

Equivalence of the two platform categories is further achieved by limiting the maximum number of pointers:

this.input.maxPointers $=1$;

This is related to mobile devices that enable keeping record of up to ten simultaneous touches, since interaction takes place with fingers instead of a mouse device.

The scripts necessary for playing the game are organized into logical units: Loading, Start, Instructions, Game, and Finish. The functions shown in Fig. 3 are used for running the game execution cycle necessary for setting up parameters and, next, for continuous interaction with the interface.

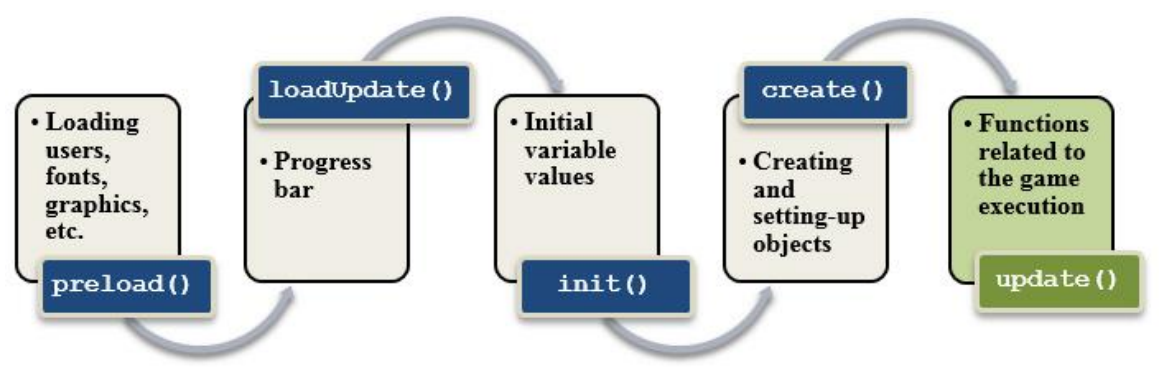

Fig. 3. The cycle in the execution of the game Zagonetke mudrog lisca

After creating the game, update () function continuously checks and executes statuses within the game. Since each call also draws content to the screen, the maximum speed is defined by the frame rate the Internet browser can achieve within the used Canvas element and its objects. Since the running time of the function depends on the device speed and its workload at the moment of execution, in order to achieve similar experience on different platforms, the implementation uses and calls time functions in precisely assigned intervals.

The specificity of running applications with continuous activity in a web browser, in which several time functions are used as in the implemented model (for calculating scores, for keeping record of the time spent in a certain part of the game), is reflected in the pronounced problem of activity gaps due to higher priority processes. For example, the time can expire in case of phone calls, SMSs, opening up of other web sites, or execution of any higher priority application. These situations are avoided by stopping all interface changes if the focus is lost (this.stage.disableVisibilitychange = false), up until other processes finish or the focus goes back to the game, which is when all the activities restart from the point they left off at. 
This approach enables using the model without loss of data. However, the downside is that students can take advantage of this by purposefully activating system pauses in order to try to solve tasks in other ways and then simply register their answers. Due to this, the model keeps records of such pauses (switching windows, i.e. pause in any of the windows).

\subsection{Analyzing platforms used for accessing the system}

The students can learn Mathematics by playing the game, but also through studying instructions related to the areas of Mathematics covered by the game, compare their results to those of other students, and communicate over the social network.

The system was accessed by 73 students, i.e. $70.19 \%$. The game was played 2847 times within the period covered by the research. Altogether 25 students posted 44 messages in total (Table 2).

Content analysis reveals that there are 23 messages expressing opinion. Only five messages were posted from desktop platforms, and 18 from mobile platforms.

The communication conducted over the social network can serve the purpose of a questionnaire on the adoption of learning Mathematics by playing computer games, considering the fact that 21 students gave positive opinion, while two students find the game difficult. No students expressed dissatisfaction with the form of learning.

Table 2. Platforms used for accessing different components of the e/m-learning system

\begin{tabular}{|l|c|c|}
\hline \multirow{2}{*}{ Platform } & \multicolumn{2}{|c|}{ System component } \\
\cline { 2 - 3 } & $\begin{array}{c}\text { Learning by playing } \\
\text { (the number of played games) }\end{array}$ & $\begin{array}{c}\text { Social network } \\
\text { (the number of messages) }\end{array}$ \\
\hline Desktop & 683 & 14 \\
\hline Mobile & 2164 & 30 \\
\hline
\end{tabular}

Some students skip the first level by purposefully making mistakes (the game ends after three wrong moves) in order to access the menu at the end of the game which enables them to check the number of medals won, see the top list (Top 20), and compare their accomplishments with other students. Due to that observation and due to the fact that the first level is used by the teachers for providing instructions and explaining different ways of solving tasks, the dataset is pre-processed by discarding records related to the sessions which end at the first level. According to the pre-processed dataset, the students played the game 683 times on desktop platforms and 2164 times on mobile platforms. It is, thus, evident that mobile platforms were used more than desktop platforms. More precisely, mobile platforms were used 3.2 times more often. Additionally, by taking into account the relationship between the number of students and the number of games played from different platforms, the statistical chi-square test shows that the difference in using these platforms is statistically significant $\left(\chi^{2}=\right.$ $7.0925, \mathrm{p}<.05)$.

The hypothesis that m-learning through educational computer games is more acceptable form of learning Mathematics for young generations of students than the equivalent e-learning is, therefore, accepted. 


\subsection{Analyzing the content of the microblog service}

Word2vec model is applied to the contents of messages, and concepts (words) are analyzed in relation to the familiar concept igra ('game'), which is a starting point or the reference term. In order to validate the model semantically, all the concepts chosen for the analysis are familiar rather than unknown or abbreviated.

In the conducted analysis, the window size is variable. Considering the fact that microblog messages contain just couple of words, the window size is set in the range from 2 to 4 . The words analyzed are those which appear at least twice (minimum occurrence $=2$ ).

The most commonly used concepts in the game Zagonetke mudrog lisca are obtained in the above-described way (rješenja, super, zadatak, fora, meaning 'solutions', 'super', 'task', 'cool', respectively). These concepts are then used for the reference term. The obtained distance vector values are given in Table 3 and shown in Fig. 4 (for the window size of 3 ).

Table 3. Distance vector values of the reference term and comparable concepts in the word $2 \mathrm{vec}$ model with respect to the window size

\begin{tabular}{|c|c|c|c|c|c|c|c|}
\hline \multirow{2}{*}{\multicolumn{2}{|c|}{$\begin{array}{l}\text { Reference term / } \\
\text { comparable concept }\end{array}$}} & \multicolumn{3}{|c|}{ CBOW Window size } & \multicolumn{3}{|c|}{ Skip-gram Window size } \\
\hline & & 2 & 3 & 4 & 2 & 3 & 4 \\
\hline \multirow{4}{*}{ Igra } & Rješenja & 0.2909 & 0.4155 & 2.2091 & 0.8093 & 1.3473 & 1.9433 \\
\hline & Super & -0.1005 & -0.1146 & -0.4428 & -0.1644 & -0.1956 & -0.5445 \\
\hline & Zadatak & 0.3977 & 0.5791 & 2.4276 & 0.9576 & 1.3951 & 1.7449 \\
\hline & Fora & -0.1818 & -0.1930 & -0.4316 & -0.2584 & -0.2753 & -0.4421 \\
\hline
\end{tabular}

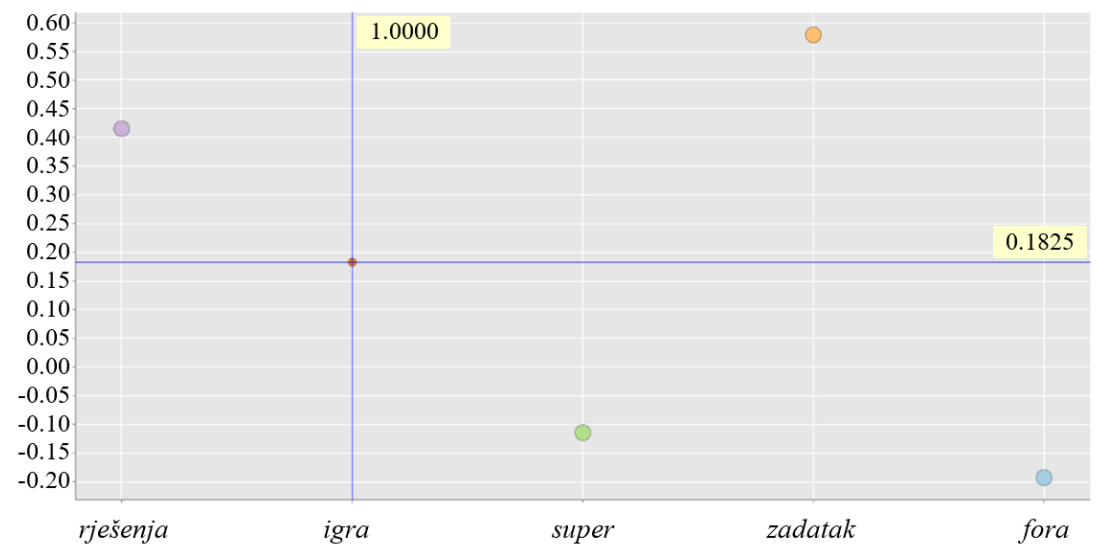

a) $\mathrm{CBOW}$ 


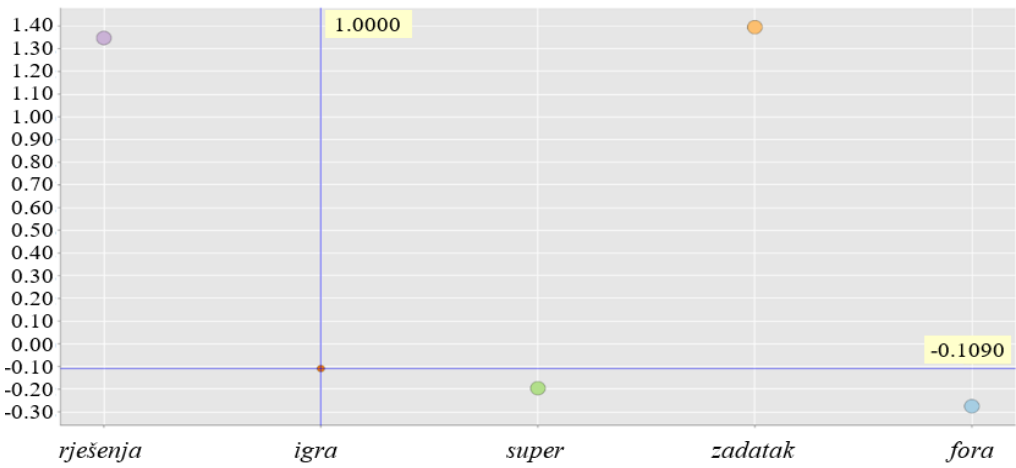

b) Skip-gram

Fig. 4. Distance vector of the reference term and comparable concepts in the word2vec model CBOW and skip-gram

Words closer in meaning are characterized by shorter distances between them (e.g. Rješenja and Zadatak on one hand, and Super and Fora on the other hand).

Fig. 5 shows relationships between comparable concepts in terms of average distances between vectors for different window sizes (2, 3, and 4).

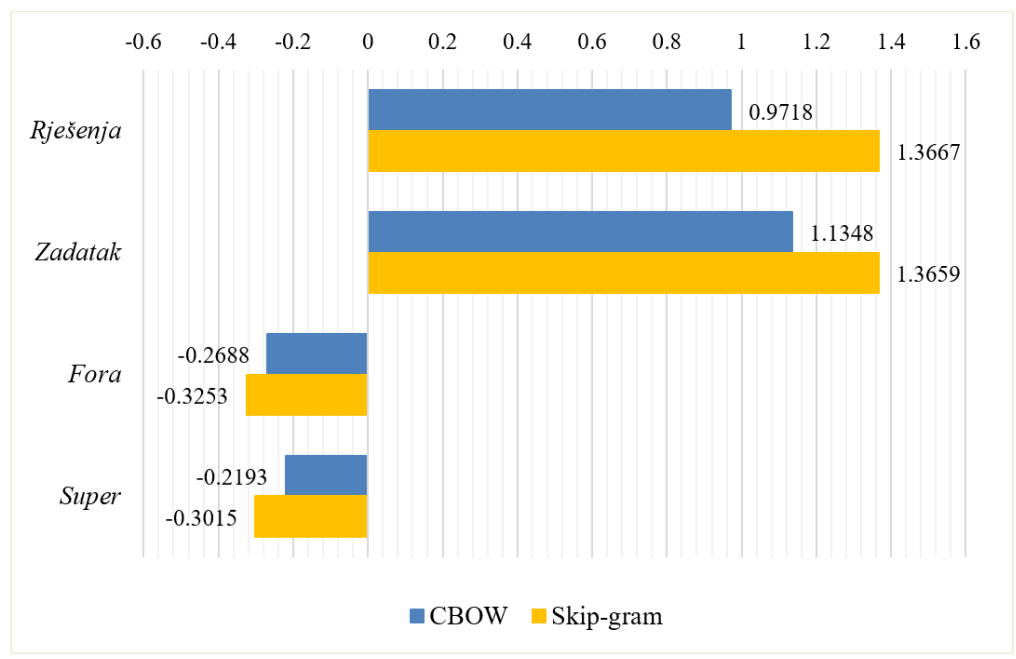

Fig. 5. Average distance of the comparable concepts in the word2vec model

This analysis shows that it is possible to group concepts of the same type and put them in a co-relationship with the known expressions. In all the analyzed cases, concepts which are semantically similar (connected: rješenje-zadatka ('task solution') or equivalent: fora-super ('super cool')) are at shorter distances than those which are 
not similar. This enables interpreting unknown concepts based on the similar known concepts because closeness implies similarity in meaning.

The obtained results show that the social network microblog texts can be analyzed with neural networks, in order to provide better understanding of student jargon and unknown concepts.

\section{$6 \quad$ Limitations and Future Work}

Although the dataset entails all four higher grades of the primary school, i.e. four generations are taken into account, the research is limited to the primary school context and to the subject field of Mathematics. Since the applied model is generic, the research design could be applied to other STEM constituents with adaptations regarding the learning content. It could be assumed that social network messages and modes of expression would differ for older generations. Therefore, future research should include high school generations as well.

The data sample obtained from the social network is admittedly small, since the access is granted only from the game interface and exclusively to authenticated users. Increasing the sample size would allow including more concepts and provide more holistic interpretation of attitudes. Furthermore, implementing other types of social networks would allow posting larger amounts of content, i.e. longer messages, in order to enable more complex social network content analysis.

\section{Conclusion}

It is challenging to motivate students for using different learning systems. The model used in this research uses computer games.

The development of the educational computer game uncovers that web technologies in the HTML5 eco-system on the client side can be used for adapting e-learning systems to m-learning by providing equivalent user experience and equal functionalities. Students always access the same content, which is then rendered in a similar way and used independently of the platform. This shows that it is possible to simplify the development of e-learning and m-learning systems because the same code base can be used, which, with minor adaptations, can lead to a wider availability of learning systems. At the same time, students can choose the platform which suits them better at any point of time. Despite the positive impact on the availability of the system, it is particularly challenging to make the application run on all dominant mobile platforms, which are additionally fragmented by different models of devices, i.e. dimensions and screen resolutions, memory availability, and all other factors affecting educational game performance. Since WebGL (which positively affects game performance, i.e. supports higher number of frames per second) is not supported by smartphone devices used by some students, choosing Canvas instead of WebGL can additionally improve m-learning availability.

The results of this research indicate that, when given a choice, students prefer mlearning to e-learning. The reason is location-independent continuous availability of the 
system due to easier access to devices, which can, in case of m-learning, be carried along. Since students more readily use platforms which they find more interesting and more accessible, m-learning through educational computer games is more acceptable form of learning Mathematics for young generations, compared to e-learning. The difference between using e-learning and m-learning is found to be statistically significant.

Finally, by processing the microblog social network content, it has been shown that neural networks can be used for putting unknown concepts in the context of the known, in order to facilitate understanding. Teachers find it important for keeping track of communication between students, since students often choose sign language, abbreviated terms, etc., over spoken language expressions. In this way, teachers become better informed of the needs of students in the education process (they can more easily detect student attitudes and their cognitive styles) so they can adapt their classes to direct them towards individual needs, and make the classes more efficient with respect to acquiring new learning materials.

\section{Acknowledgement}

This research has been supported under the Grant No. uniri-drustv-18-122 of the University of Rijeka and by the Centre for Artificial Intelligence and Cybersecurity of the University of Rijeka.

\section{$9 \quad$ References}

[1] HTML5 Differences from HTML4 (2014). [Online]. Available: https://www.w3.org/ TR/html5-diff [Accessed 2 December 2020].

[2] Responsive Web Design - Introduction (2014). [Online]. Available: https://www.w3schools.com/css/css_rwd_intro.asp [Accessed 2 December 2020].

[3] Dhyab, R. \& Varol, A. (2018). Distance Education Features using Facebook. International Journal of Interactive Mobile Technologies (iJIM), 12(6): 19-34. https://doi.org/10.3991/ iiim.v12i6.9621

[4] Clark, R.C. \& Mayer, R.E. (2016). e-Learning and the Science of Instruction. Proven Guidelines for Consumers and Designers of Multimedia Learning, 4th Edition, Wiley. https://doi.org/10.1002/9781119239086

[5] Hubackova, S. (2015). History And Perspectives of Elearning. Procedia - Social and Behavioral Sciences, 191: 1187-1190. https://doi.org/10.1016/j.sbspro.2015.04. 594

[6] Basak, S.K.; Wotto, M. \& Bélanger, P. (2018). E-learning, M-learning and D-learning: Conceptual definition and comparative analysis. E-Learning and Digital Media, 15(4): 191216. https://doi.org/10.1177/2042753018785180

[7] Elkins, D. \& Pinder, D. (2015). E-Learning Fundamentals, A Practical Guide. Association for Talent Development Press, Alexandria, USA.

[8] Luaran J.; Samsuri N.N.; Nadzri, F.A. \& Rom, K.B.M. (2014). A Study on the Student's Perspective on the Effectiveness of Using e-learning. Procedia - Social and Behavioral Sciences, 123: 139-144. https://doi.org/10.1016/j.sbspro.2014.01.1407

[9] Bernacki, M.L.; Crompton, H. \& Greene, J.A. (2020). Towards convergence of mobile and psychological theories of learning. Contemporary Educational Psychology, 60(101828): 17. https://doi.org/10.1016/i.cedpsych.2019.101828 
[10] Shah, A.; Hassan, S.E.B.; Kob, C.G.C. \& Khairudin, M. (2019). Effectiveness of mLearning Applications for Design and Technology Subject. International Journal of Interactive Mobile Technologies (iJIM), 13(10): 120-133. https://doi.org/10.3991/ijim. v13i10.11324

[11] Kosturko, L.; Sabourin, J.; McQuiggan, J. \& McQuiggan, S. (2015). Mobile Learning: A Handbook for Developers, Educators, and Learners. Wiley, New Jersey, USA. https://doi.org/10.1002/9781118938942

[12] Sobral, S.R. (2020). Mobile Learning in Higher Education: A Bibliometric Review. International Journal of Interactive Mobile Technologies (iJIM), 14(11): 153-170. https://doi.org/10.3991/ijim.v14i11.13973

[13] Romero-Rodríguez, J.M.; Aznar-Díaz, I.; Hinojo-Lucena, F.J. \& Cáceres-Reche, M.P. (2020). Models of good teaching practices for mobile learning in higher education. Palgrave Communications, 6(80): 1-7. https://doi.org/10.1057/s41599-020-0468-6

[14] Shchedrina, E.; Galkina, E.; Petunina, I. \& Lushkov, R. (2020). Integration of Mobile Learning into Complex Problem-Solving Processes During STEM Education. International Journal of Interactive Mobile Technologies (iJIM), 14(21): 19-36. https://doi.org/10.3991/ ijim.v14i21.18463

[15] Zhampeissova, K.; Kosareva, I. \& Borisova, U. (2020). Collaborative Mobile Learning with Smartphones in Higher Education. International Journal of Interactive Mobile Technologies (iJIM), 14(21): 4-18. https://doi.org/10.3991/ijim.v14i21.18461

[16] Kalogiannakis, M. \& Papadakis, S. (2019). Evaluating pre-service kindergarten teachers' intention to adopt and use tablets into teaching practice for natural sciences. International Journal of Mobile Learning and Organisation (IJMLO), 13(1): 113-127. https://doi.org/10.1504/ijmlo.2019.096479

[17] Papadakis, S. (2020). Robots and Robotics Kits for Early Childhood and First School Age. International Journal of Interactive Mobile Technologies (iJIM), 14(18): 34-56. https://doi.org/10.3991/ijim.v14i18.16631

[18] Fessakis, G.; Karta, P. \& Kozas, K. (2018). Designing Math Trails for Enhanced by Mobile Learning Realistic Mathematics Education in Primary Education. International Journal of Engineering Pedagogy (iJEP), 8(2): 49-63. https://doi.org/10.3991/ijep.v8i2.8131

[19] Papadakis, S. (2018). Evaluating pre-service teachers' acceptance of mobile devices with regards to their age and gender: a case study in Greece. International Journal of Mobile Learning and Organisation (IJMLO), 12(4): 336-352. https://doi.org/10.1504/ijmlo. 2018.095130

[20] Tang, Y. \& Hew, K.F. (2017). Using Twitter for education: Beneficial or simply a waste of time? Computers \& Education, 106: 97-118.https://doi.org/10.1016/j.compedu.2016.12.004

[21] Twitter API Data dictionary: Standard v1.1 (2017). [Online]. Available: https://developer.twitter.com/en/docs/tweets/data-dictionary/overview/intro-to-tweetjson[Accessed 8 December 2020].

[22] Berestova, A.; Alizade, T. \& Umirzakova, Z. (2020). The Role of Social Networks in the Educational Process. International Journal of Emerging Technologies in Learning (iJET), 15(22): 121-133. https://doi.org/10.3991/ijet.v15i22.16889

[23] Abella-García, V.; Delgado-Benito, V.; Ausín-Villaverde, V. \& Hortigüela-Alcalá, D. (2019). To tweet or not to tweet: Student perceptions of the use of Twitter on an undergraduate degree course. Innovations in Education and Teaching International, 56(4): 402-411. https://doi.org/10.1080/14703297.2018.1444503

[24] Antons, D.; Grünwald, E.; Cichy, P. \& Salge, T.S. (2020). The application of text mining methods in innovation research: current state, evolution patterns, and development priorities. R \& D Management 50(3): 329-351. https://doi.org/10.1111/radm.12408

[25] Süzen, N.; Gorban, A.N.; Levesley, J. \& Mirkes, E.M. (2020). Automatic short answer grading and feedback using text mining methods. Procedia Computer Science, 169: 726743. https://doi.org/10.1016/j.procs.2020.02.171 
[26] Tseng, C.; Chou, J. \& Tsai, Y. (2018). Text Mining Analysis of Teaching Evaluation Questionnaires for the Selection of Outstanding Teaching Faculty Members. In: IEEE Access, 6: 72870-72879. https://doi.org/10.1109/access.2018.2878478

[27] Nguyen, Q.; Rienties, B. \& Toetenel, L. (2017). Mixing and Matching Learning Design and Learning Analytics. In: Zaphiris, P. \& Ioannou, A. (eds) Learning and Collaboration Technologies. Technology in Education. LCT 2017. Lecture Notes in Computer Science, Springer, Cham, 10296: 302-316. https://doi.org/10.1007/978-3-319-58515-4 24

[28] [28] Acosta, J. et al. (2017). Sentiment Analysis of Twitter Messages Using Word2Vec. Proceedings of Student-Faculty Research Day, CSIS, Pace University, C8:1-7.

[29] Phaser - Desktop and Mobile HTML5 game framework (2020). [Online]. Available: https://phaser.io [Accessed 8 December 2020].

[30] Davey, R. (2017). Otismo Child - A free educational games bundle specifically created for children with autism. [Online]. Available: https://phaser.io/news/2017/03/otsimo [Accessed 8 December 2020].

[31] Nima, U.; Wangdi, R. \& Hauge, J.B. (2018). A Serious Game for Competence Development in Internet of Things and Knowledge Sharing. 2018 IEEE International Conference on Industrial Engineering and Engineering Management (IEEM), Bangkok, 1786-1790. https://doi.org/10.1109/ieem.2018.8607737

[32] Berthold, M.R. et al. (2009). KNIME - The Konstanz information miner: Version 2.0 and Beyond. ACM SIGKDD Explorations Newsletter, 11(1): 26-31. https://doi.org/10.1145/ $\underline{1656274.1656280}$

[33] Mikolov, T.; Chen, K.; Corrado, G. \& Dean, J. (2013). Efficient Estimation of Word Representations in Vector Space. Proceedings of the International Conference on Learning Representations (ICLR 2013), 1-12.

[34] Arumugam, R. \& Shanmugamani, R. (2018). Hands-On Natural Language Processing with Python: A practical guide to applying deep learning architectures to your NLP applications. Packt Publishing, Birmingham, UK.

[35] Deshpande, A. \& Kumar, M. (2018). Artificial Intelligence for Big Data: Complete guide to automating Big Data solutions using Artificial Intelligence techniques. Packt Publishing, Birmingham, UK.

[36] Jurić, P; Bakarić, M.B. \& Matetić, M. (2018). Design and Implementation of Anonymized Social Network-based Mobile Game System for Learning Mathematics. International Journal of Emerging Technologies in Learning (iJET), 13(12): 83-98. https://doi.org/10. $\underline{\text { 3991/ijet.v13i12.8762 }}$

\section{Authors}

Petar Juric earned his $\mathrm{PhD}$ degree at the Department of Informatics of the University of Rijeka. He works as Head of ICT Department of Primorje-Gorski Kotar County in Croatia. Email: petar_jur@yahoo.com

Marija Brkic Bakaric is an assistant professor and a senior research associate at the Department of Informatics of the University of Rijeka.

Maja Matetic is a full professor at the Department of Informatics of the University of Rijeka.

Article submitted 2021-02-19. Resubmitted 2021-04-26. Final acceptance 2021-04-27. Final version published as submitted by the authors. 